\title{
Mechanical behavior of a titanium alloy scaffold mimicking trabecular structure
}

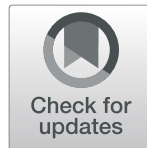

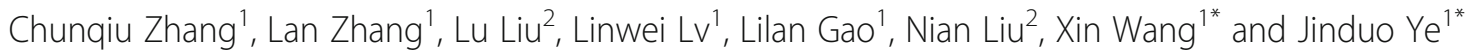

\begin{abstract}
Background: Additively manufactured porous metallic structures have recently received great attention for bone implant applications. The morphological characteristics and mechanical behavior of 3D printed titanium alloy trabecular structure will affect the effects of artificial prosthesis replacement. However, the mechanical behavior of titanium alloy trabecular structure at present clinical usage still is lack of in-depth study from design to manufacture as well as from structure to mechanical function.
\end{abstract}

Methods: A unit cell of titanium alloy was designed to mimick trabecular structure. The controlled microarchitecture refers to a repeating array of unit-cells, composed of titanium alloy, which make up the scaffold structure. Five kinds of unit cell mimicking trabecular structure with different pore sizes and porosity were obtained by modifying the strut sizes of the cell and scaling the cell as a whole. The titanium alloy trabecular structure was fabricated by 3D printing based on Electron Beam Melting (EBM). The paper characterized the difference between the designs and fabrication of trabecular structures, as well as mechanical properties and the progressive collapse behavior and failure mechanism of the scaffold.

Results: The actual porosities of the EBM-produced bone trabeculae are lower than the designed, and the load capacity of a bearing is related to the porosity of the structure. The larger the porosity of the structure, the smaller the stiffness and the worse the load capacity is. The fracture interface of the trabecular structure under compression is at an angle of $45^{\circ}$ with respect to the compressive axis direction, which conforms to Tresca yield criterion. The trabeculae-mimicked unit cell is anisotropy. Under quasi-static loading, loading speed has no effect on mechanical performance of bone trabecular specimens. There is no difference of the mechanical performance at various orientations and sites in metallic workspace. The elastic modulus of the scaffold decreases by $96 \%-93 \%$ and strength reduction 96\%-91\%, compared with titanium alloy dense metals structure. The apparent elastic modulus of the unit-cell-repeated scaffold is $0.39-0.618 \mathrm{GPa}$, which is close to that of natural bone and stress shielding can be reduced.

Conclusion: We have systematically studied the structural design, fabrication and mechanical behavior of a 3D printed titanium alloy scaffold mimicking trabecula bone. This study will be benefit of the application of prostheses with proper structures and functions.

Keywords: 3D printing, Unit cell, Trabecula bone, Porosity, Experimental research

\footnotetext{
*Correspondence: wangxin_tju@hotmail.com; Jinduoyetj@126.com

${ }^{1}$ Tianjin Key Laboratory for Advanced Mechatronic System Design and

Intelligent Control, National Demonstration Center for Experimental

Mechanical and Electrical Engineering Education, Tianjin, University of

Technology, Tianjin 300384, People's Republic of China

Full list of author information is available at the end of the article
}

(c) The Author(s). 2020 Open Access This article is distributed under the terms of the Creative Commons Attribution 4.0 International License (http://creativecommons.org/licenses/by/4.0/), which permits unrestricted use, distribution, and reproduction in any medium, provided you give appropriate credit to the original author(s) and the source, provide a link to the Creative Commons license, and indicate if changes were made. The Creative Commons Public Domain Dedication waiver (http://creativecommons.org/publicdomain/zero/1.0/) applies to the data made available in this article, unless otherwise stated. 


\section{Introduction}

At present, 3D printing technology has developed vigorously in the medical field $[1,2]$ and has been successfully used in orthopedic treatment $[3,4]$. The 3D printing technology cannot only realize the individualized manufacture of medical devices, but also is superior to the traditional technology in the construction of the microstructures of implants $[5,6]$. It can make titanium alloy $[7,8]$ and other metal powders into fabricate three-dimensional porous metal implants (metal trabeculae) with different porous structures, whose microstructure is similar to human bone trabecula, and whose porosity, pore size, pore volume, spatial arrangement and other surface properties as well as elastic modulus can be completely determined by design $[9,10]$. The trabecular bone structure greatly improves the bioactivity of implants, it has high pore connectivity and is conducive to the adhesion, proliferation and differentiation of osteoblasts [11-13]. At the same time, it can guide bone tissue to grow into the pore and form implantbone bio-fixation. The bonding strength with bone interface increases by about three times compared with that of dense metal implants [14-17]. In addition, the interconnected porous structure is conducive to the transport and circulation of body fluids and nutrients, speeding up tissue healing, and improving the biological stability of implants in the short term. With the development of 3D printing technology and new biological materials, the application of trabecular structure in artificial joint replacement [18] is increasing, and the design, fabrication and mechanical properties of trabecular structures are the focus of current research [19].

The morphological characteristics and mechanical behavior of 3D printed titanium alloy trabecular structure will affect the effects of artificial prosthesis replacement, therefore, the aspects need to be further researched. Wang Chunxiao [20] et al. designed and manufactured titanium alloy scaffolds with different pore structures using metal 3D printing technology, and observed its micro-pore characteristics and mechanical properties. Sakkadech Limmahakhun [21, 22] et al. taking the cylindrical octahedron structure as a unit, fabricated four kinds of porous structures with different pore size by Selective laser melting technology, and testing their mechanical properties and biological behavior. $\mathrm{Li} \mathrm{X}$ [23] et al. studied the surface properties [24, 25], mechanical properties [26, 27], and its biological behavior [28, 29] of porous titanium alloy made by electron beam melting (EBM). However, the mechanical behavior of titanium alloy trabecular structure at present stage of clinical usage still lacks of in-depth study, from design to manufacture, from structure to mechanical function.
In this paper, 3D printed titanium alloy scaffold mimicking trabecular structure was fabricated by EBM. The differences between design and manufacture, the effects of different porosity and pore size on compressive mechanical properties and the mechanism of structural damage are studied.

\section{Materials and methods \\ Fabrication of scaffold specimens}

The overall structure and the building unit cells were selected, as shown in Fig. 1a. The unit cell called "Fine Strut 2.0", as the original structure, which can be exactly contained in a square body with a side length of $\mathrm{L}=2.0 \mathrm{~mm}$, is rhombic and the strut size of that is $0.1467 \mathrm{~mm}$. By scaling the original structure as a whole, that is to say, by changing the worth of " $\mathrm{L}$ " to obtain "Fine Strut 1.75" and "Fine Strut 2.5". In addition, the strut size of the original structure increases to $0.2739 \mathrm{~mm}$ to obtain "Mid Strut 2.0", then which is magnified 1.25 times as a whole to get "Mid Strut 2.5 ". Five scaffolds with different pore sizes and porosities were obtained. Copy the unit cells respectively along the $\mathrm{x}, \mathrm{y}$ and $\mathrm{z}$ axes, and then perform Boolean operations on them. Five kinds of cuboid scaffolds with cross section size of $10 * 10 \mathrm{~mm}$ and height of $20 \mathrm{~mm}$ were established with these five cells as units, respectively. Cuboid scaffold specimens (Provided by Tianjin Just Huajian Medical Devices Co., Ltd.) were prepared by EBM with Ti6Al4V titanium alloy powder as raw material. The design dimensions are shown in Table 1.

\section{Microstructural characterization}

High temperature melting and solidification of metal powders can cause intracellular bending and ripple, resulting in geometric irregularity and uneven surface. The trabecular structure of titanium alloy under high magnifier is shown in Fig. 1b.

The strut size and aperture of scaffold specimens were measured by digital image correlation equipment (2DDIC), including high magnifying lens, computer and data processing software. Measure the strut size and aperture of the image in the display window with vernier caliper. Measure three places and then take the average value. Finally divide the magnification factor to calculate the actual size.

The projection of scaffold specimens in the vertical direction can only be observed under a high magnifying glass. The observed "pore" is not the real pore of the scaffold, but its projected pore in the vertical direction. For ease of comparison, both the scaffold model and the manufactured scaffold specimens measured the aperture and strut size under projection. 


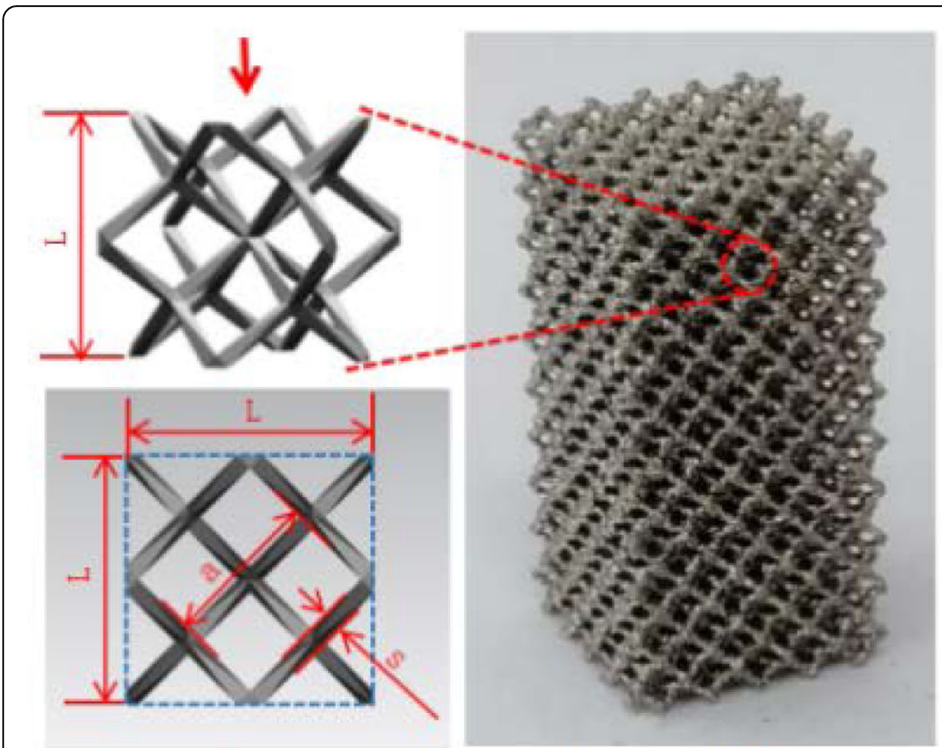

(a)unit cell and titanium alloy scaffold

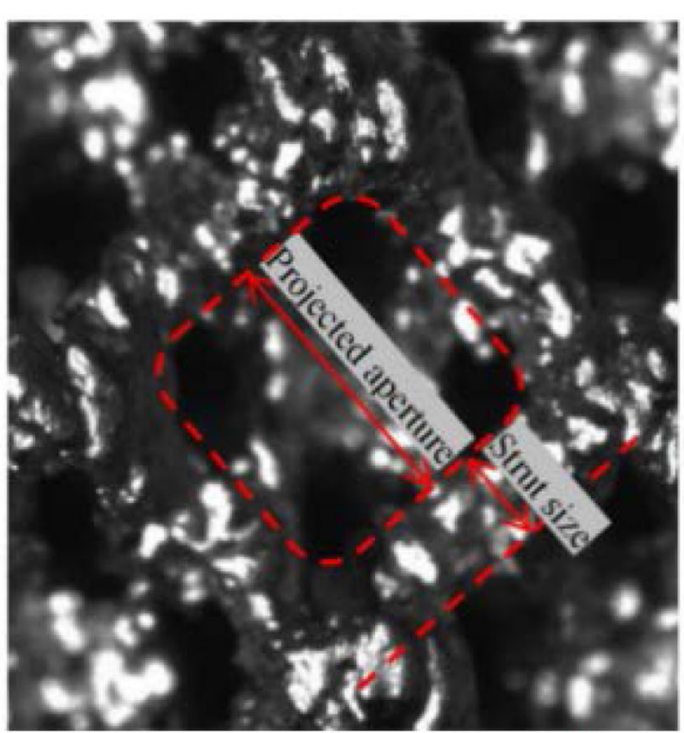

(b)micro morphology of scaffold

Fig. 1 Titanium alloy scaffold built by unit cell ( $L$, a and $s$ are unit, projected aperture and strut size, respectively) and micro morphology of titanium alloy scaffolds mimicking bone trabeculae. a unit cell and titanium alloy scaffold, $\mathbf{b}$ micro morphology of scaffold

Dense cylindrical titanium alloy specimens also were fabricated by 3D printing. The diameter of cross section is $20 \mathrm{~mm}$, and the height of specimen is $113 \mathrm{~mm}$. The volume of the specimen was measured by vernier caliper and the mass of that was obtained by high precision balance weighing. Finally the density of 3D printed dense titanium alloy material was obtained by volume and mass calculation. This density is used to calculate the actual porosity of 3D printed titanium alloy scaffold specimens.

\section{Mechanical tests}

Quasi-static uniaxial compression tests were carried out on the fabricated scaffold specimens using the electronic universal testing machine (Changchun Kexin Test Instrument Co., Ltd. Type WDW-10).

The correlation between porosity and mechanical properties were studied on scaffold specimens with different aperture and porosity at the same loading speed. The compression tests included researching the anisotropy of specimens under the same loading speed from two different loading directions as well as the effects of different loading speeds on mechanical properties. Moreover, the mechanical properties of specimens taken from different 9 locations and 3 orientations of the 3D printer' working space were studied.

\section{Data analysis}

The experimental data from the mechanical test was analyzed. Descriptive statistics were used to summarize sample characteristics and our primary variables of interest. All data analysis is done in Matlab. A one-way analysis of variance (ANOVA) was carried out to determine the statistical variances among the contact pressure, peak contact pressure and contact area of different loading rates and different loads for the intact samples and defect samples, respectively. Test data used in the figures represented mean values, while the standard errors above and below mean values were indicated by error bars.

Table 1 Design size of cellular structure and theoretical porosity corresponding of scaffold specimens

\begin{tabular}{lllllll}
\hline Cell specifications & $\mathrm{L} / \mathrm{mm}$ & Strut size $/ \mathrm{mm}$ & Aperture $/ \mathrm{mm}$ & Projected aperture/mm & Specimen size/mm & Theoretical porosity of specimens/\% \\
\hline Fine Strut 1.75 & 1.75 & 0.1284 & 0.6571 & 1.1090 & $10 \times 10 \times 20$ & 96.065 \\
Fine Strut 2.0 & 2.0 & 0.1467 & 0.7511 & 1.2676 & $10 \times 10 \times 20$ & 96.07 \\
Fine Strut 2.5 & 2.5 & 0.1834 & 0.9388 & 1.5843 & $10 \times 10 \times 20$ & 96.066 \\
Mid Strut 2.0 & 2.0 & 0.2739 & 0.6615 & 1.1403 & $10 \times 10 \times 20$ & 87.415 \\
Mid Strut 2.5 & 2.5 & 0.3424 & 0.8269 & 1.4254 & $10 \times 10 \times 20$ & 87.414 \\
\hline
\end{tabular}


Table 2 Actual strut size, aperture and porosity of five different specifications of scaffold specimens

\begin{tabular}{llll}
\hline Specimen specifications & Strut size/mm & Projected aperture/mm & Actual porosity/\% \\
\hline Fine Strut 1.75 & 0.4 & 0.766667 & 61.444 \\
Fine Strut 2.0 & 0.4037037 & 0.9814814 & 72.608 \\
Fine Strut 2.5 & 0.396296 & 1.318519 & 79.665 \\
Mid Strut 2.0 & 0.407407 & 0.944444 & 65.083 \\
Mid Strut 2.5 & 0.407407 & 1.292593 & 74.461 \\
\hline
\end{tabular}

\section{Results}

\section{Microstructural characterization}

The density of 3D printed dense titanium alloy material is $4.3541037 \mathrm{~g} / \mathrm{cm}^{3}$ calculated from 3D printed dense cylindrical specimens. The actual strut size, aperture and porosity of the prepared scaffold specimens are shown in Table 2.

As can be seen from Table 2, in both the series of fine strut and the series of mid strut, the projected aperture and porosity increase with the increase of cell size L. The aperture of Fine Strut 2.0 is similar to that of Mid Strut 2.0, and the aperture of Fine Strut 2.5 is similar to that of Mid Strut 2.5.The porosity of Fine Strut 1.75 is similar to that of Mid Strut 2.0, and the porosity of Fine Strut 2.0 is similar to that of Mid Strut 2.5. The porosity of Fine Strut 2.5 is the largest.

Figure 2 visually shows the difference between the design value and the actual value of the scaffold specimen. It can be seen that the porosity produced by $3 \mathrm{D}$ printing is always lower than that designed.

\section{Mechanical properties}

The morphology of the compression process is shown in Fig. 3a-c.

As shown in Fig. 3d, the compression stress-strain curves of 3D printed titanium scaffold specimens are divided into four stages. The first three stages had the three stage characteristic of the typical stress-strain curve of the foam metal compressed [30], that is, the obvious linear elastic deformation stage $\mathrm{OA}$, the yield plateau stage $A B$ and the compact stage $B C$. In the first stage, that the linear elastic deformation stage OA, under compressive loading, struts of cells of scaffold structure first undergoes micro-bending (Fig. 4a). After reaching the critical stress, it enters the second stage, that the yield plateau stage AB. At this stage, cells' struts further deforms. Firstly, microcracks appear at the corner of the cell structure, and the original diamondshaped pores becomes flattened (Fig. 4b). At this time, the internal stress does not continue to increase but the strain continues to increase, that is, a stress platform appears and the specimen undergoes plastic deformation, which is due to the plastic hinge occurring at the maximum bending moment of metal bone trabecula, which is the elastic-plastic body. Therefore, the continuous strain behavior of the metal bone trabecula near a fixed stress value is shown as the yield platform stage on the stress-strain curve. Its deformation cannot be restored. When the load on the specimens reaches the yield limit, it enters the third stage, that the compact stage BC. There are many cracks breeds on cells' struts, and the cracks on the corner become larger or even break (Fig. 4c). From the macroscopic point of view, it can be seen that some of the struts are twisted, but the failure

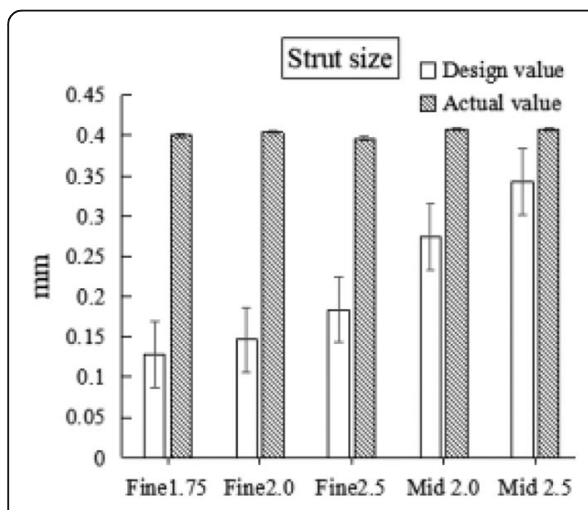

(a)

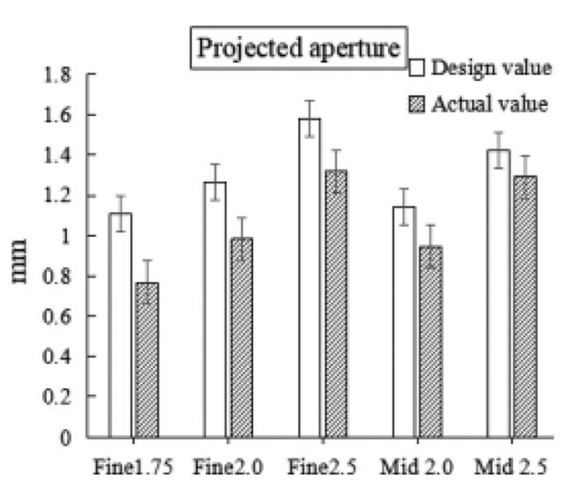

(b)

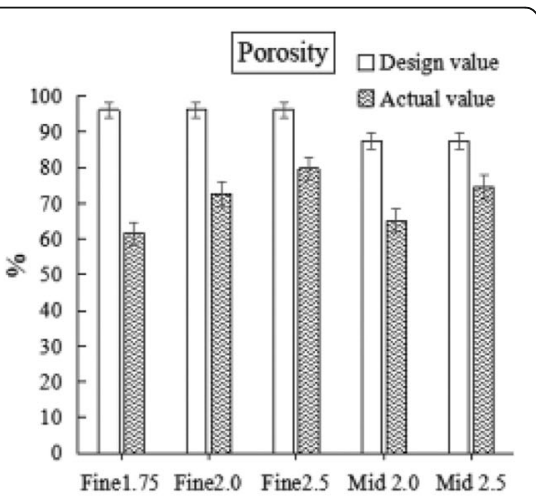

(c)

Fig. 2 Comparison between design value and actual value of scaffold specimen. (a) Strut size, (b) Projected aperture, (c) Porosity 

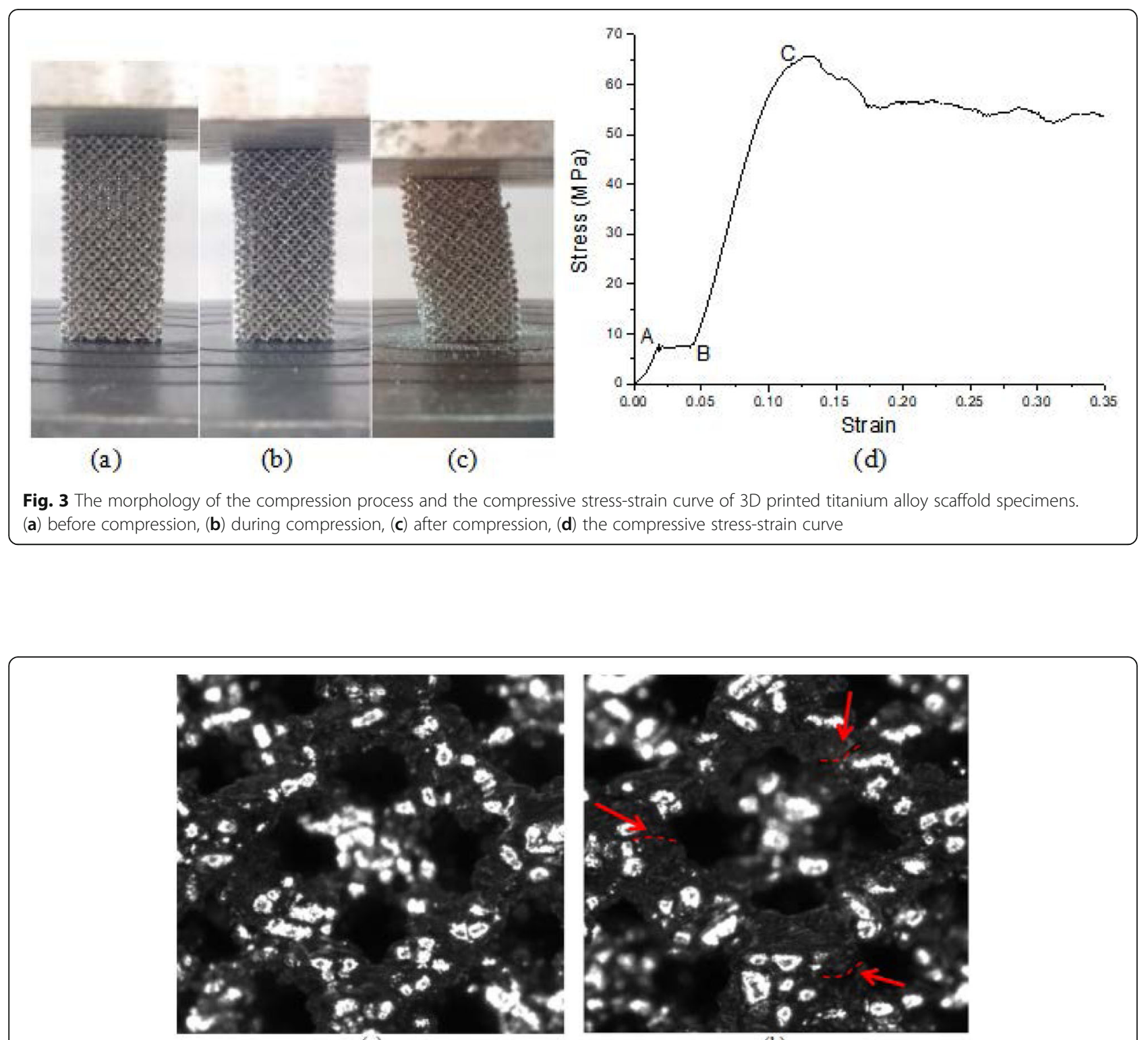

(a)
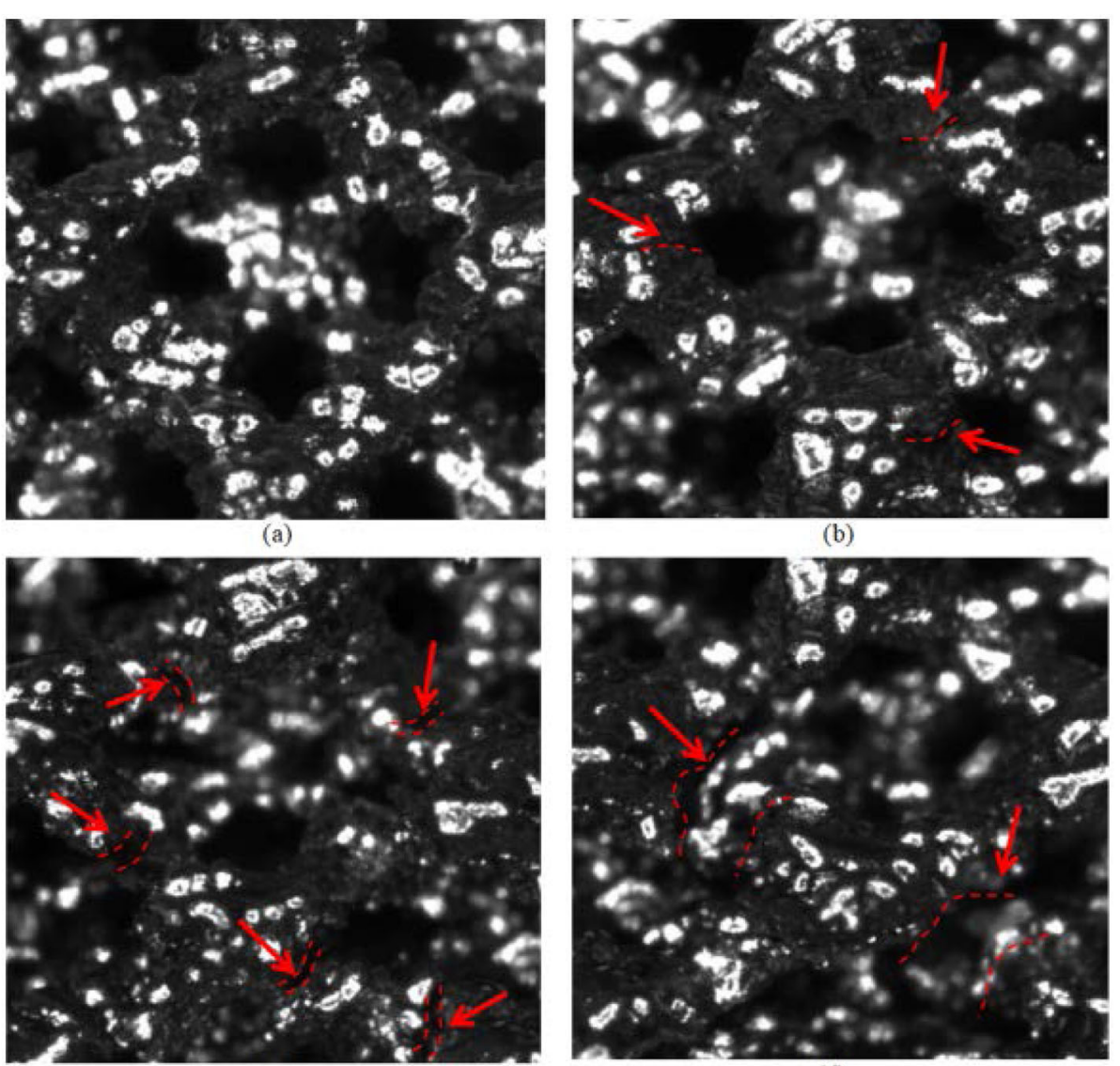

(c)

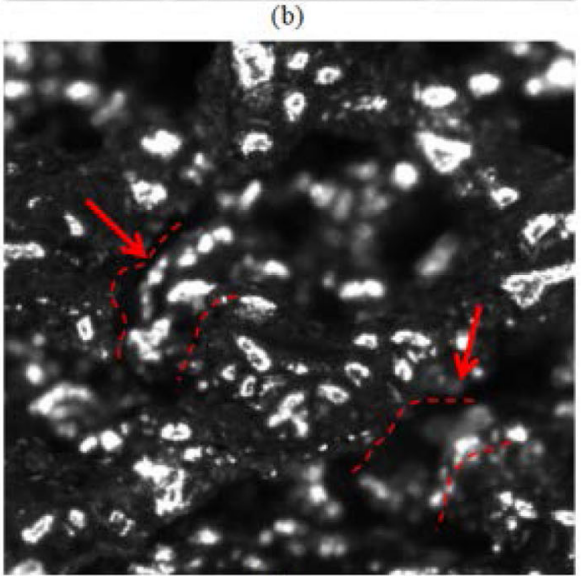

(d)

Fig. 4 Crack initiation and propagation during compression process (the red dotted line in the figure represents the crack). (a) the first stage, (b) the second stage, (c) the third stage, (d) the fourth stage 

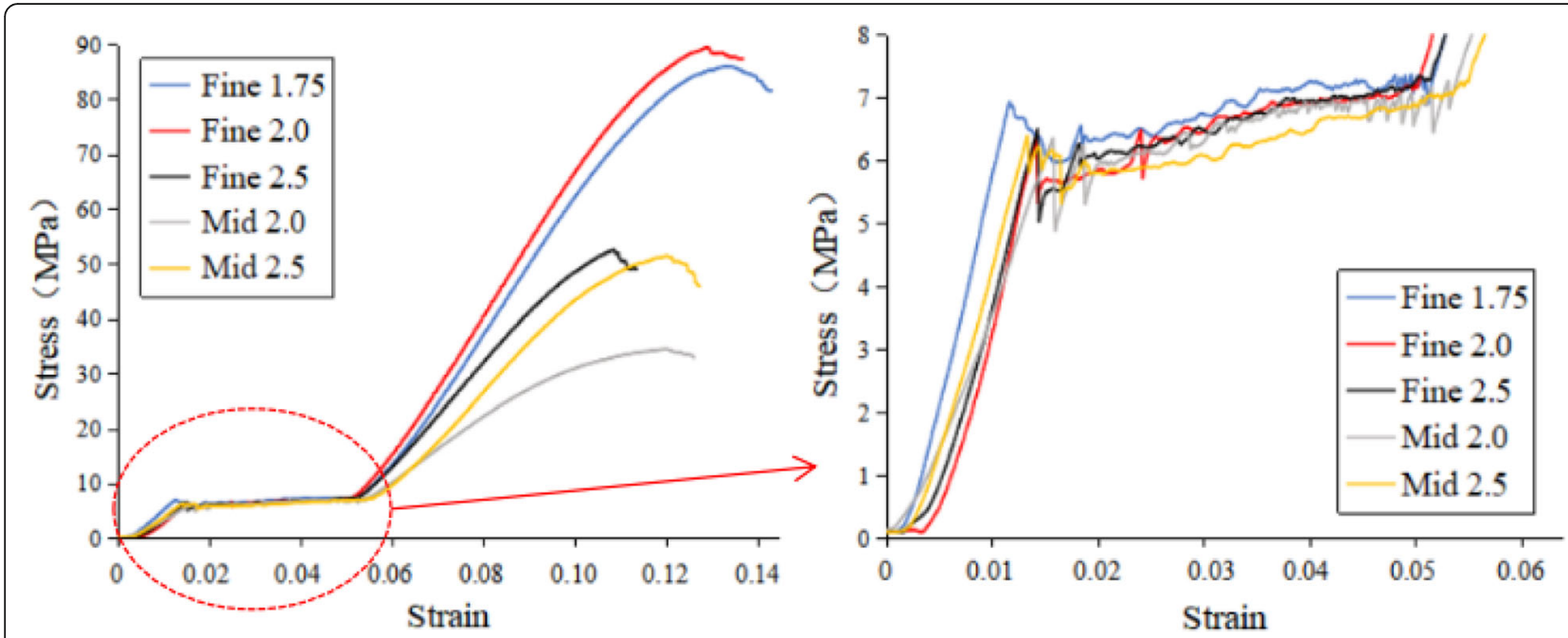

Fig. 5 Compressive stress-strain curves and local enlargement maps of scaffold specimens of different specifications

of the specimens is not obvious (Fig. 3b). In the fourth stage, that the crushing stage $C$, some cells' struts are broken and collapsed (Fig. 4d).

\section{The effects of different aperture and porosity on mechanical}

\section{properties}

Compressive stress-strain curves of scaffold specimens of different specifications are shown in Fig. 5. It can be clearly seen from it that the load-carrying capacity changes with the increase of cell size $\mathrm{L}$, in both the series of fine strut and the series of mid strut. The loadcarrying capacity of Fine Strut 1.75 is similar to that of Fine Strut 2.0, and the load-carrying capacity of Fine Strut 2.5 is similar to that of Mid Strut 2.5. The bearing capacity of Mid Strut 2.0 is the worst.

The compression performance of the structure is shown in Table 3 . It can be seen from the table that the maximum force, compressive strength, yield force, yield strength and modulus of elasticity (stiffness) change with the increase of cell size L in both the series of fine strut and the series of mid strut. Its structural stiffness ranges from 437 to $659 \mathrm{MPa}$, and the corresponding compressive strength ranges from 30.27 to $80.34 \mathrm{MPa}$.

\section{Anisotropy of structure}

Taking scaffold specimens whose specifications are "Fine strut 2.0" to implement longitudinal compression and transverse compression respectively, the scaffold structure shown the anisotropy. The stress-strain curves of longitudinal and transverse compression (Fig. 6c) are similar in shape but do not coincide. From the elastic stage, the elastic modulus of longitudinal compression is obviously higher than that of transverse compression. Therefore, the more the number of cells parallel to the compressive load, the greater the load-carrying capacity of the scaffold structure is.

Measurement by digital image correlation equipment (as shown in Fig. 6a-b), the Poisson's ratio of the trabecular structure was calculated to be 1.23 , as shown in Table 4.

\section{The effects of different loading speeds on mechanical properties}

When the scaffold of "Fine Strut 2.0" is compressed longitudinally, the stress-strain curve obtained at the loading speed of $0.5 \mathrm{~mm} / \mathrm{min}$ and $2 \mathrm{~mm} / \mathrm{min}$ is shown in Fig. 7a, and the stress-strain curve obtained at the loading speed of $1 \mathrm{~mm} / \mathrm{min}$ and $5 \mathrm{~mm} / \mathrm{min}$ is shown in

Table 3 Compression experimental data of scaffold specimens

\begin{tabular}{llllll}
\hline Specimen specifications & Maximum Force $(\mathrm{N})$ & Compressive Strength (MPa) & Yield Force (N) & Yield Strength (MPa) & Modulus of Elasticity (Mpa) \\
\hline Fine Strut 1.75 & 8480.09 & 77.07 & 8405.78 & 76.39 & 659.33 \\
Fine Strut 2.0 & 8717.44 & 80.34 & 8632.83 & 79.44 & 628.78 \\
Fine Strut 2.5 & 4724.88 & 43.01 & 4444.3 & 40.59 & 548.69 \\
Mid Strut 2.0 & 3421.05 & 30.27 & 3254.2 & 32.32 & 437.09 \\
Mid Strut 2.5 & 5081.16 & 47.06 & 5004.23 & 46.34 & 545.22 \\
\hline
\end{tabular}




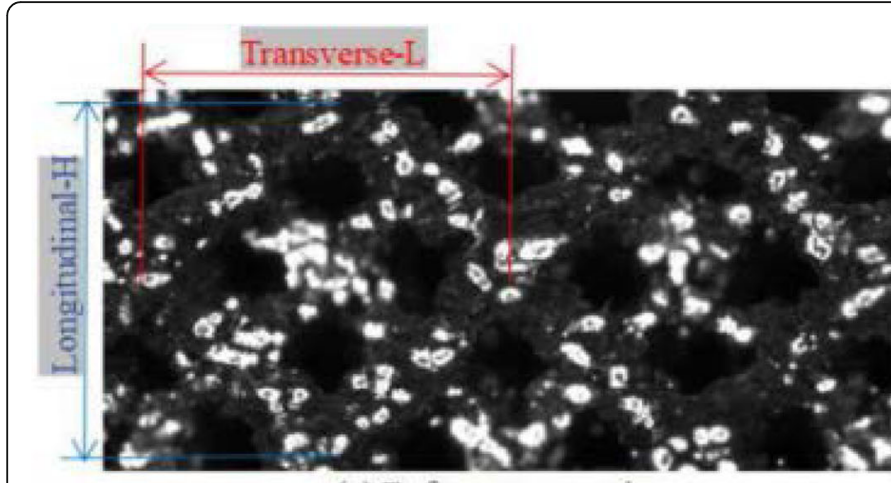

(a) Before compression
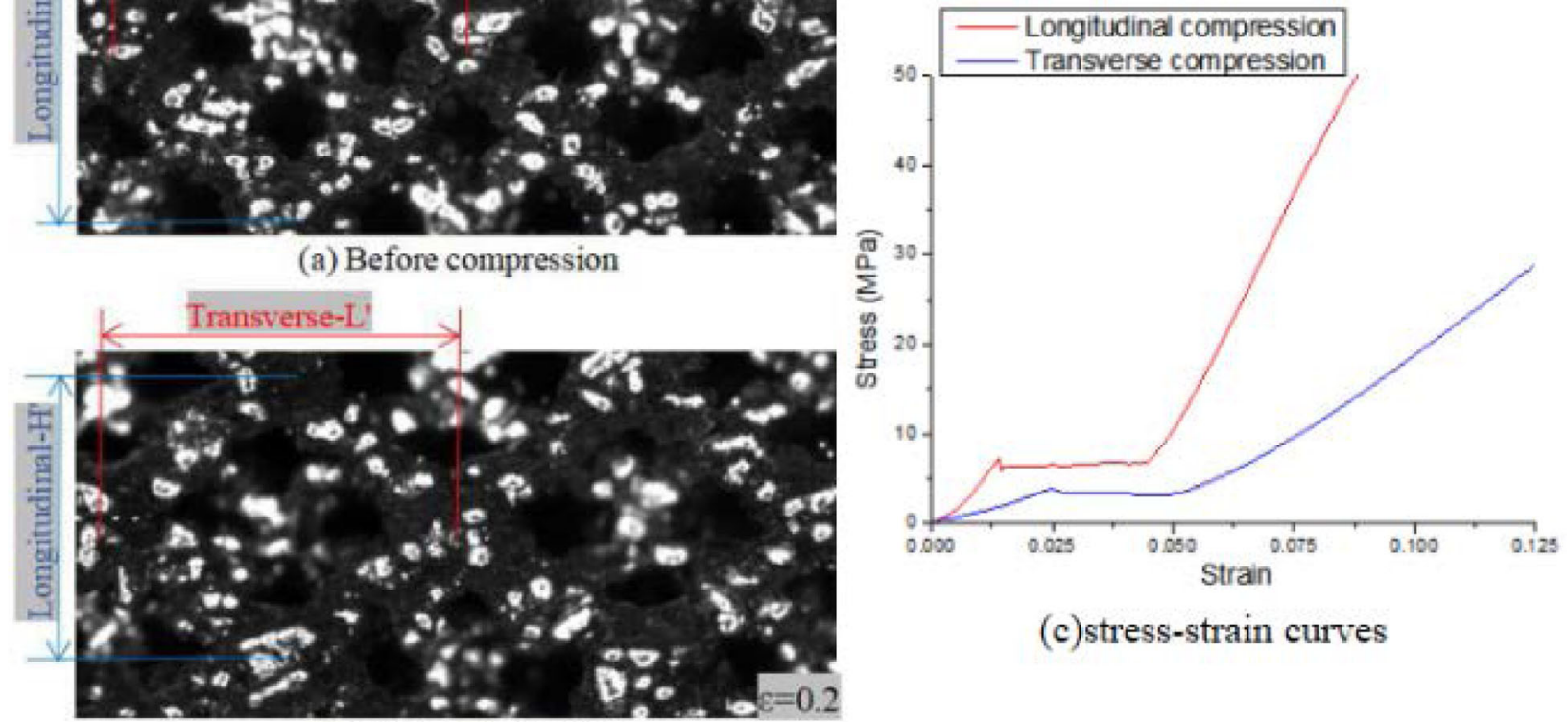

(b) After compression

(c)stress-strain curves

Fig. 6 Calculating Poisson ratio of this structures and the comparison of stress-strain curves between longitudinal and transverse compression. (a) before compression, (b) after compression, (c) the compressive stress-strain curve

Fig. 7b. It can be seen that the stress-strain curves of two specimens with the same specification are similar under two different loading speeds, which indicates that the loading speed has little effects on the mechanical properties of the specimens under quasi-static loading conditions.

The differences in mechanical properties of specimens taken from different directions and sites of 3D printers'working space

A batch of scaffold specimens whose specifications are "Fine strut 2.0" were manufactured by $3 \mathrm{D}$ printing, which were taken from nine locations in the 3D printer's workspace, respectively. The nine directions are: ZQS, ZQX, ZHS, ZHX, ZJ, YQS, YQX, YHS and YHX. There are three specimens in each direction, a total of 27 specimens. The effect of different printer locations on mechanical properties of specimens was studied.
The compressive stress-strain curves with the same loading speed of 9 specimens whose specifications are "Fine strut 2.0" from 9 locations of 3D printer and their local magnification figures are shown in Fig. 8. The stress-strain curves of the specimens printed on the nine directions of the $3 \mathrm{D}$ printer are similar in shape and have little difference, which indicates that the different directions of the 3D printer have little effect on the mechanical properties of the specimens.

\section{Failure mechanism}

It was found by experiment that, whether longitudinal or lateral compression, the failure is mainly caused by shear stress of 45 degrees.

The curve shape of crushing stage, namely the fourth stage of the stress-strain curve (as shown in Fig. 8), can be roughly summarized into the following four types. The first one, if struts of cells is broken evenly and no

Table 4 Measured data and calculation of Poisson ratio of this scaffolds

\begin{tabular}{|c|c|c|c|c|c|}
\hline & Transverse dimension (mm) & Longitudinal dimension (mm) & Transverse strain & Longitudinal strain & Poisson ratio \\
\hline Before compression & $L=0.1589$ & $H=0.1578$ & 0.9717 & 0.7883 & 1.23 \\
\hline After compression $(\varepsilon=0.2)$ & $L^{\prime}=0.1544$ & $H^{\prime}=0.1244$ & & & \\
\hline
\end{tabular}




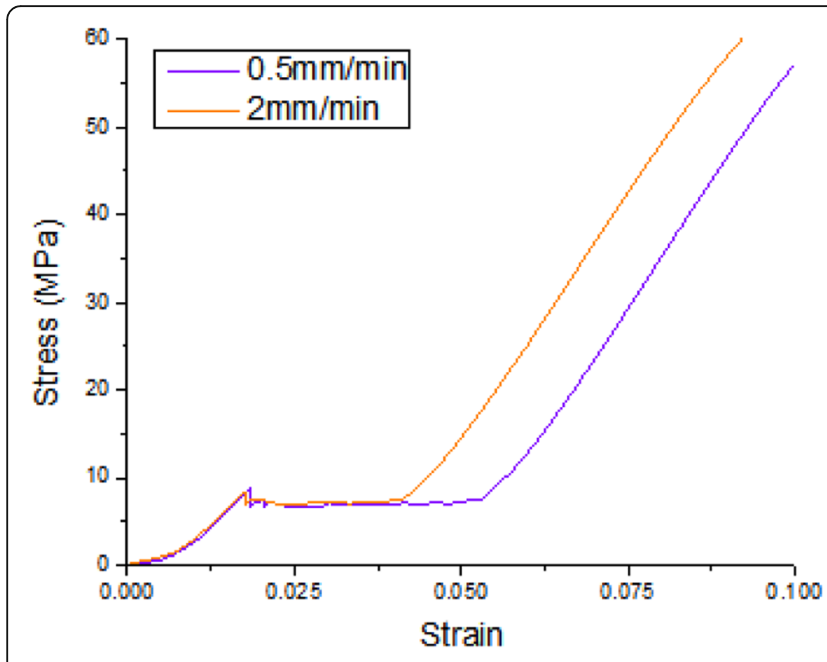

(a) Longitudinal compression

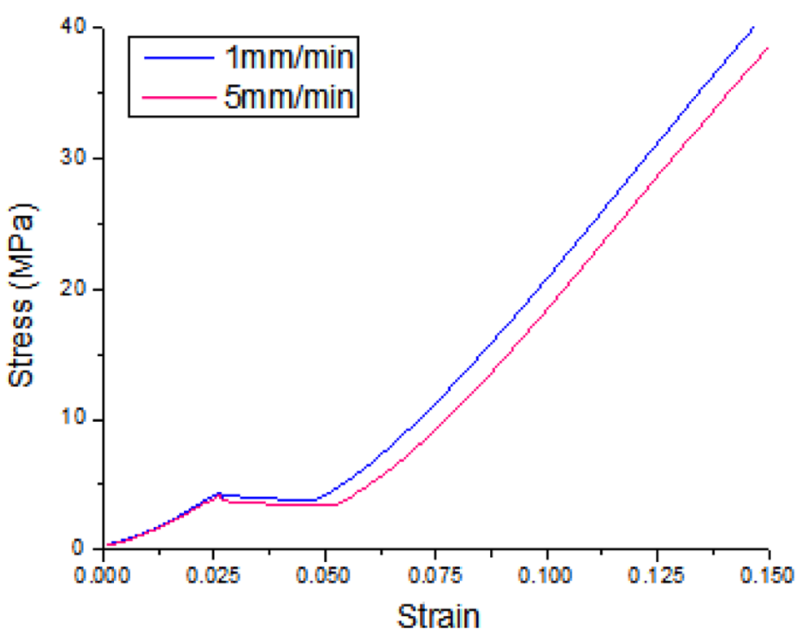

(b) Transverse compression

Fig. 7 The comparison of compressive stress-strain curves at different loading speeds. (a) longitudinal compression, (b) transverse compression

large block collapses during compression, there is a long microwavy stress "platform" shown as Fig. 8-YQS. After compression, the specimen is relatively complete and the damaged part still stick to the main block (Fig. 8a). The second one as morphology of the specimen after compression shown in Fig. 8b, if a small part of cells structure is broken but not collapse and completely disconnected from the whole, the stress increases gradually and tends to be wavy "platform" as shown in Fig. 8ZHX. The third one, if the structure breaks entirely during compression, the stress decreases as microwave fluctuation (Fig. 8-ZQX). The overall fracture surface is $45^{\circ}$ inclined to the loading direction, while, the inclined plane is uneven (Fig. 8c), which is the most common situation appeared in the experiments. The last one, if brittle fracture occurs the stress drops sharply (Fig. 8$\mathrm{ZJ})$. The whole fracture surface is $45^{\circ}$ inclined and the inclined plane is very smooth (Fig. 8d-e).

\section{Discussion}

We systematically studied a $3 \mathrm{D}$ printed titanium alloy scaffold mimicking trabecular structure, from its structural design, fabrication to the mechanical behavior. At present, the structures and functions are the focus of clinical application. The porosity of scaffold manufactured by EBM is lower than that of design. The bearing capacity of scaffold is related to the porosity of the structure. The fracture interface of the scaffold is $45^{\circ}$ inclined to the loading direction, which conforms to Tresca yield criterion. The scaffold mimicking trabecular structure are anisotropic. The loading speed has no effect on the mechanical properties of the specimens under quasi-static loading conditions. Structural morphology is related to the bioactivity of implants. The proper porosity and connectivity are conducive to the adhesion, proliferation and differentiation of osteoblasts, and can guide bone tissue to grow into the pore. Mechanical behavior is related to the effectiveness of mechanical transmission of prostheses.

Compared with 3D printed dense titanium alloy materials, the elastic modulus and strength of $3 \mathrm{D}$ printed titanium alloy bone trabeculae are greatly reduced.

Tensile specimens of 3D printed dense titanium alloy were tested. After 3D printing, heat treatment was carried out to eliminate prestressing force. There were a total of 18 specimens distributed in 9 different locations on the 3D printer'workspace. The specimen is cylindrical with crosssectional diameter of $5 \mathrm{~mm}$ and length of $25 \mathrm{~mm}$ respectively. The stress-strain of specimens curve is obtained by tensile test. The tensile test data are shown in Table 5.

Tensile tests of 3D printed Titanium alloy dense specimens show that there are obvious yielding and necking phenomena, as displayed in plastic materials. The strength of the material is higher, approaching $1 \mathrm{GPa}$, however, the elastic modulus is lower with the average value of $10 \mathrm{GPa}$, which is close to the mechanical properties of forged titanium alloy (1000 MPa/110GPa). Compared with the high strength and low elastic modulus of 3D printed dense titanium alloy specimens, the elastic modulus and strength of 3D printed porous titanium alloy decreases by $96 \%$ 93\% and $96 \%$ - 91\% respectively. The apparent modulus of elasticity is $0.39-0.618 \mathrm{GPa}$, which indicates that the mechanical propertie of bone trabeculae with this porous structure are closer to that of human bone, and stress shielding can be reduced effectively.

This paper systematically correlates the scaffold structure to mechanical behavior of a 3D printed titanium 

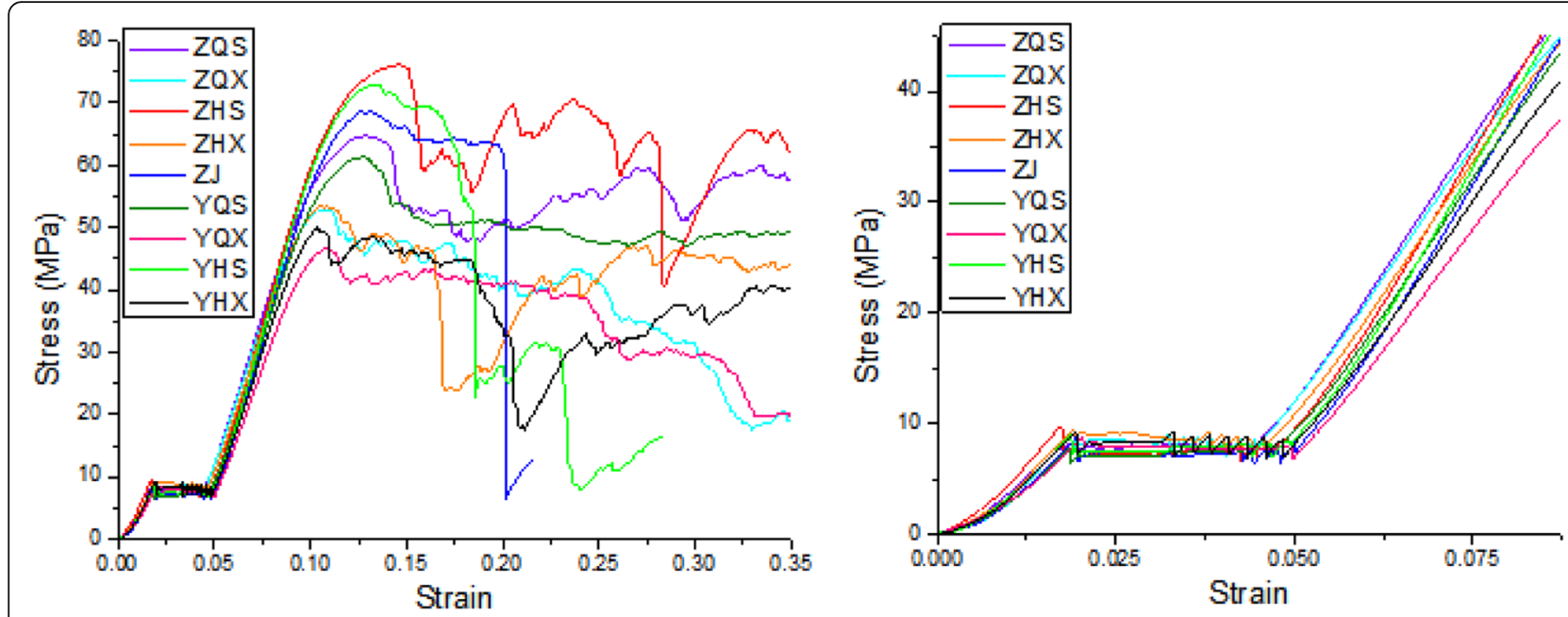

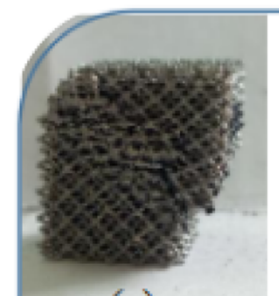

(a)

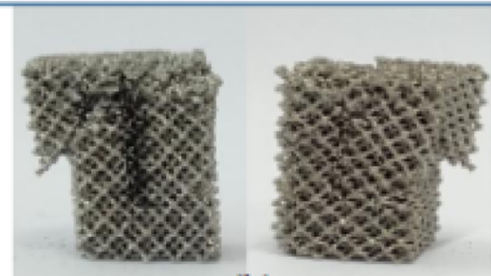

(b)

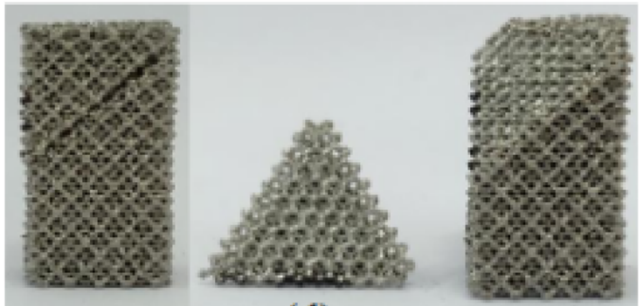

(d)
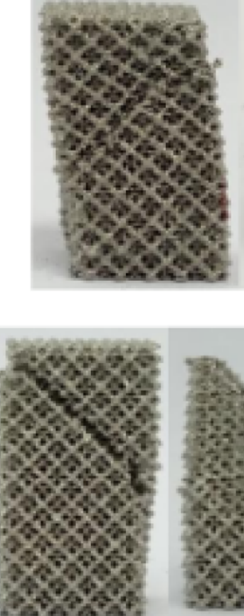

(c)
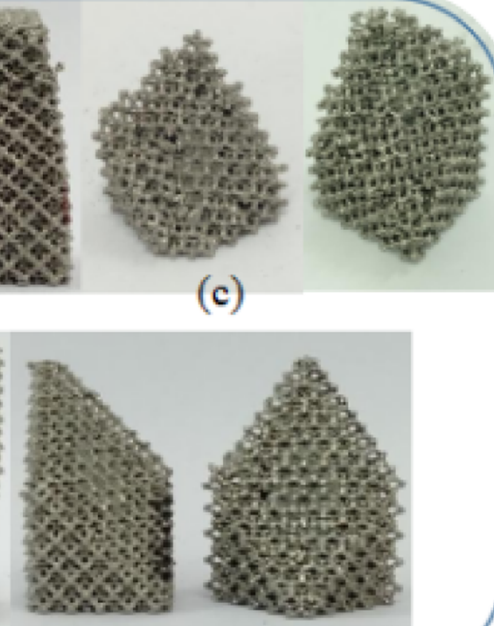

(e)

Fig. 8 Compressive stress-strain curves of 9 specimens from 9 different locations and their local magnification maps, and fracture morphology of some specimens. the (a) to (e) are the fracture patterns of five specimens

alloy scaffold, aiming at mimicking the mechanical properties of natural trabecula for tissue engineering. However, it is more or less ignored that the biological and physiological function of the osteoblast seeded in the titanium alloy porous scaffold and the interaction between cells and surface, which will be the future focus in the following study.

\section{Conclusion}

Titanium alloy is widely used in the field of clinical bone implants due to its excellent biocompatibility, biological safety and mechanical strength. It is an ideal material for the production of artificial joint prosthesis and bone joint products. The parameters of 3D printed titanium alloy scaffold, such as aperture, porosity, pore shape and surface treatment, have an important effect on bone growth and osteoblast performance in vitro. We have systematically studied the structural design, fabrication and mechanical behavior of a 3D printed titanium alloy scaffold mimicking trabecula bone. This study may shed a light on the application of prostheses with proper structures and functions.

Table 5 Result data of Tensile Tests of 3D printed titanium alloy dense specimens (Data Average of 18 Specimens)

\begin{tabular}{lcccccc}
\hline $\begin{array}{l}\text { Maximum force } \\
(\mathrm{N})\end{array}$ & $\begin{array}{l}\text { Tensile strength } \\
(\mathrm{MPa})\end{array}$ & $\begin{array}{l}\text { Lower yield force } \\
(\mathrm{N})\end{array}$ & $\begin{array}{l}\text { Lower yield strength } \\
(\mathrm{MPa})\end{array}$ & $\begin{array}{l}\text { Elongation at break } \\
(\%)\end{array}$ & $\begin{array}{l}\text { Section shrinkage } \\
(\%)\end{array}$ & $\begin{array}{l}\text { Modulus of elasticity } \\
(\mathrm{MPa})\end{array}$ \\
\hline $20,137.5$ & 1014.3 & $19,457.6$ & 980.1 & 13.12 & 29.84 & $10,088.49$ \\
\hline
\end{tabular}




\section{Abbreviation}

EBM: Electron beam melting

\section{Acknowledgments \\ Not applicable.}

\section{Authors' contributions}

CZ and XW contributed to the conception and design of the study. LZ, LLiu and LLV implemented the experiments and acquisition of data. LG and NL performed the analysis of data. XW and JY draft the article, JY contributed to the experiment method and revised manuscript critically for important intellectual content. All authors in charge of (1) acquisition of data and data analysis and image processing, (2) drafting the manuscript or revising it critically for important intellectual content; (3) giving final approval of the version to be published. Each author has participated sufficiently in the work to take public responsibility for appropriate portions of the content. All authors read and approved the final manuscript.

\section{Funding}

The project was partly supported by the National Natural Science Foundation of China $(11432016,11702191)$ and Tianjin Science Foundation (18ZXSGSY00010, 18YFZCSY00890,18JCZDJC36100).

\section{Availability of data and materials}

Data and materials presented in this paper can be shared upon request.

\section{Ethics approval and consent to participate}

There is no ethics problems in our experiments and article.

\section{Consent for publication}

Not applicable.

\section{Competing interests}

The authors declare that they have no competing interests.

\section{Author details}

'Tianjin Key Laboratory for Advanced Mechatronic System Design and Intelligent Control, National Demonstration Center for Experimental Mechanical and Electrical Engineering Education, Tianjin, University of

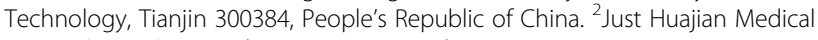
Device (Tianjin) Co., Ltd., Tianjin 300190, China.

Received: 13 May 2019 Accepted: 27 November 2019

Published online: 07 February 2020

\section{References}

1. Yan $\mathrm{Q}$, Dong H, Su J, Han J, Song B, Wei Q, et al. A review of 3 D printing technology for medical applications. Engineering. 2018;4(5):729-42 https:// www.sciencedirect.com/science/article/pii/S2095809917306756.

2. Wang C, Zhang W, Li Z. Development of additive manufacturing in medical devices. Orthop Biomech Mater Clin Study. 2013;10(06):26-8. https://doi.org/ 10.3969/j.issn.1672-5972.2013.06.008 http://kns.cnki.net//KXReader/ Detail?TIMESTAMP $=636933752152585000 \& D B C O D E=C J F Q \& T A B L E N a m e=$ CJFDHIS2\&FileName=SWGK201306012\&RESULT $=1 \& S I G N=4 y j y Q o j \% 2 b X b y \% 2$ bxP9dP8oMowrZ644\%3d\&UID=WEEvREdxOWJmbC9oM1 NjYkZCbDdrdWdXNUoyeW5ZOWZ4OTU4WEpaNzVPU1I=\$R1yZOH6jyaaOen3 RxVUd8df-oHi7XMMDo7mtKT6mSmEvTuk1112gFA!! Chinese Journal: (王彩 梅, 张卫平, 李志疆. 3D打印在医疗器械领域的应用.生物骨科材料与临床 研究. 2013;10(6):26-28).

3. Eltorai AEM, Nguyen E, Daniels AH. Three-dimension printing in orthopedic surgery. Orthopedics. 2015;38(11):684-7.

4. Martelli N, Serrano C, van den Brink H, et al. Advantages and disadvantages of 3dimensional printing in surgery: a systematic review. Surgery. 2016;159(6):1485.

5. Luo L, Yu S, Yu Z, Liu C, Han J, Niu J. Application and research of titanium alloy human implants prepared by 3D printing. Titan Ind Prog. 2015;32(05):1-6 http:// kns.cnki.net//KXReader/Detail?TIMESTAMP=636933733315866250\&DBCODE= CJFQ\&TABLEName=CJFDLAST2015\&FileName $=$ TGYJ201505001\&RESULT $=$ $1 \& S I G N=2 F v s S i l A c y T K x \mid 7 V y x c f k V n i E X o \% 3 d \& U I D=W E E v R E d x O W J m b C 9 o M 1$ NjYkZCbDdrdWdXNUoyeW5ZOWZ4OTU4WEpaNzVPU11=\$R1yZOH6jyaaOen3 RxVUd8df-oHi7XMMDo7mtKT6mSmEvTuk11/2gFA!! Chinese Journal:(罗丽娟,余
森, 于振涛,刘春潮, 韩建业, 牛金龙.3D打印钛合金人体植入物的应用与研究. 钛工业进展.2015;32(05):1-6).

6. $\quad$ Sing SL, An J, Yeong WY, et al. Laser and electron-beam powderbed additive manufacturing of metallic implants: a review on processes, materials and designs. J Orthop Res. 2016;34(3):369-85.

7. Nover AB, Lee SL, Georgescu MS, et al. Porous titanium bases for osteochondral tissue engineering. Acta Biomater. 2015;27:286-93.

8. Ren X, Ma B, Zhang B, Zhang Y, Yu J, Qu X. Research progress of porous titanium and titanium alloy. Rare Metals Cemented Carbides. 2018;46(01):6164+75 http://kns.cnki.net//KXReader/Detail?TIMESTAMP=6369337599603975 00\&DBCODE=CJFQ\&TABLEName=CJFDLAST2018\&FileName=XYJY201801014 \&RESULT $=1 \& S I G N=$ ehsXc2f2RXqjh20LpxCa5NTFFGM\%3d\&UID= WEEvREdxOWJmbC9oM1NjYkZCbDdrdWdXNUoyeW5ZOWZ4OTU4 WEpaNzVPU1I=\$R1yZ0H6jyaaOen3RxVUd8df-oHi7XMMDo7mtKT6mSmEvTuk11 I2gFA!! Chinese Journal:(任金明，马北越,张博文,张亚然于景坤,曲选辉.多孔 钛及钛合金的研究进展. 稀有金属与硬质合金.2018;46(01):61-64+75).

9. Biemond JE, Aquarius R, Verdonschot N, et al. Frictional and bone ingrowth properties of engineered surface topographies produced by electron beam technology. Arch Orthop Trauma Surg. 2011;131(5):711-8.

10. Hazlehurst K, Wang C, Stanford M. Evaluation of the stiffness characteristics of square pore CoCrMo cellular structures manufactured using laser melting technology for potential orthopaedic applications. Mater Des. 2013;51:94955 https://www.sciencedirect.com/science/article/pii/S0261306913004342.

11. Taniguchi N, Fujibayashi S, Takemoto M, et al. Effect of pore size on bone ingrowth into porous titanium implants fabricated by additive manufacturing: An in vivo experiment. Mater Sci Eng C. 2016;59:690-701.

12. Van Bael S, Chai YC, Truscello S, et al. The effect of pore geometry on the in vitro biological behavior of humanperiosteum-derived cells seeded on selective laser-melted Ti6Al4V bone scaffolds. Acta Biomater. 2012;8(7):2824-34.

13. Wang Z, Wang C, Liu H, Li C, Qin Y, Cai X, et al. Effects of three-dimensional printed porous titanium scaffolds on bone ingrowth. Chin J Tissue Eng Res. 2016;20(52):7821-8. https://doi.org/10.3969/j.issn.2095-4344.2016.52.010 http://kns.cnki.net//KXReader/Detail?TIMESTAMP=6369337782853975 00\&DBCODE $=$ CJFQ\&TABLEName $=$ CJFDLAST2017\&FileName $=$ XDKF201652

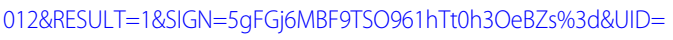
WEEvREdxOWJmbC9oM1NjYkZCbDdrdWdXNUoyeW5ZOWZ4OTU4 WEpaNzVPU1I=\$R1yZOH6jyaaOen3RxVUd8df-oHi7XMMDo7mtKT6 mSmEvTuk1112gFA!! Chinese Journal:(王中汉，王辰宇，刘贺，李忱，秦彦国、蔡 晓宇,等.3D打印钛合金孔隙支架骨长入影响因素的分析.中国组织工程研 究.2016;20(52):7821-7828).

14. Chen Y. Bone regeneration performance of trabecular-like 3D porous titanium implants fabricated by additive manufacturing: an in vivo study. Chongqing Medical University. 2017. http://kreader.cnki.net/Kreader/ CatalogViewPage.aspx?dbCode=cdmd\&filename $=1017844396$. nh\&tablename $=$ CMFD201801\&compose $=\&$ first $=1 \&$ uid $=$ WEEvREdxOWJmbC9oM1NjYkZCbDdrdWdXNUoyeW5ZOWZ4OTU4 WEpaNzVPU1I=\$R1yZOH6jyaaOen3RxVUd8df-oHi7XMMDo7mtKT6 mSmEvTuk11l2gFA!! Chinese Journal: (陈宇. 基于激光三维打印的类骨小梁 多孔钛种植体的设计及其体内成骨效应研究. 重庆医科大学.2017).

15. Li JP, Habibovic $P$, van den Doel $M$, et al. Bone ingrowth in porous titanium implants produced by 3D fiber deposition. Biomaterials. 2007;28(18):2810-20.

16. Van der Stok J, Van der Jagt OP, Amin Yavari S, et al. Selective laser meltingproduced porous titanium scaffolds regenerate bone in critical size cortical bone defects. J Orthop Res. 2013;31(5):792-9.

17. LV J, Jia Z, Li J, et al. Electron beam melting fabrication of porous Ti6Al4V scaffolds: cytocompatibility and osteogenesis. Adv Eng Mater. 2015;17(9):1391-8.

18. Mont Michael A, Krebs Viktor E, Backstein David J, et al. Artificial intelligence: influencing our lives in joint arthroplasty. J Arthroplast. 2019;34(10):2199.

19. Wu T, Yang C. Research progress of three-dimensional printing porous scaffolds for bone tissue engineering. Chin J Reparative Reconstr Surg. 2016; 30(04):509-13. https://doi.org/10.7507/1002-1892.20160101 http://kns.cnki. net//KXReader/Detail?TIMESTAMP=636933763546960000\&DBCODE $=$ CJFQ\&TABLEName $=$ CJFDLAST2016\&FileName $=$ ZXCW201604034\&RESULT $=$ $1 \& S I G N=\mid Y f 99 V 5 g t J a r 5 m 5 b Q K E 6 j d z h \% 2 b h M \% 3 d \& U I D=$ WEEvREdxOWJmbC9oM1NjYkZCbDdrdWdXNUoyeW5ZOWZ4OTU4 WEpaNzVPU1I=\$R1yZ0H6jyaaOen3RxVUd8df-oHi7XMMDo7mtKT6 mSmEvTuk1112gFA!! Chinese Journal: (吴天琦,杨春喜.可用于骨修复的3-D 打印多孔支架研究进展.中国修复重建外科杂志.2016;30(04):509-513).

20. Wang C, Li X, Luo Y. Design and strength analysis of porous titanium scaffold. J Shanghai Jiaotong Univ. 2016;50(02):165-8. https://doi.org/10. 16183/j.cnki.jsjtu.2016.02.001 http://kns.cnki.net//KXReader/ 
Detail?TIMESTAMP=636933768557897500\&DBCODE $=$ CJFQ\&TABLEName= CJFDLAST2016\&FileName $=$ SHJT201602001\&RESULT $=1 \& S I G N=j 3 B R V 4 f \% 2$ brWmdcMAbPoemGmdo $1 \mathrm{mg} \% 3 \mathrm{~d} \&$ UID =WEEvREdxOWJmbC9oM1 NjYkZCbDdrdWdXNUoyeW5ZOWZ4OTU4WEpaNzVPU11=\$R1yZOH6jyaaOen3 RxVUd8df-oHi7XMMDo7mtKT6mSmEvTuk1 1/2gFA!! Chinese Journal:(王春 晓, 李祥,罗云. 多孔钛合金支架结构设计及其抗压强度分析.上海交通大学 学报.2016;50(02):165-168).

21. Limmahakhun S, Oloyede A, Sitthiseripratip K, Xiao Y, Yan C. 3D-printed cellular structures for bone biomimetic implants. Addit Manuf. 2017;15:93101 https://www.sciencedirect.com/science/article/pii/S2214860416301865\#!

22. Limmahakhun S, Oloyede A, Sitthiseripratip K, Xiao Y, Yan C. Stiffness and strength tailoring of cobalt chromium graded cellular structures for stressshielding reduction. Mater Des. 2017;114:633-41 https://www.sciencedirect. com/science/article/pii/S0264127516314915.

23. Li X, Ma X-Y, Feng Y-F, Lin Wang B, Wang C. A novel composite scaffold consisted of porous titanium and chitosan sponge for load-bearing applications: fabrication, characterization and cellular activity. Compos Sci Technol. 2015;117:78-84.

24. Li X, Wang C, Zhang W, et al. Fabrication affabrication, characterization and cellund characterization of porous Ti6Al4V parts for biomedical applications using electron beam melting process. Mater Lett. 2009;63(3-4):403-5.

25. Li X, Ma XY, Feng YF, et al. Osseointegration of chitosan coated porous titanium alloy implant by reactive oxygen species-mediated activation of the PI3K/AKT pathway under diabetic conditions. Biomaterials. 2015;36:44-54

26. Li X, Wang C, Zhang W, et al. Fabrication and compressive properties of Ti6Al4V implant with honeycomb-like structure for biomedical applications. Rapid Prototyp J. 2010;16(1):44-9.

27. Li X, Wang CT, Zhang WG, et al. Properties of a porous Ti-6Al-4V implant with a low stiffness for biomedical application. Proc Inst Mech Eng H J Eng Med. 2009;223(2):173-8.

28. Xiang L, Ya-Fei F, Cheng-Tao W, et al. Evaluation of biological properties of electron beam melted Ti6Al4V implant with biomimetic coating in vitro and in vivo. PLoS One. 2012;7(12):e52049.

29. Li X, Wang L, Yu X, et al. Tantalum coating on porous Ti6Al4V scaffold using chemical vapor deposition and preliminary biological evaluation. Mater Sci Eng C. 2013;33(5):2987-94.

30. Zhang J. Mechanical properties and breakage mechanism of cellular materials. Xiangtan University. 2003. http://kreader.cnki.net/Kreader/ CatalogViewPage.aspx?dbCode $=$ cdmd\&filename $=2006162894$. nh\&tablename $=$ CDFD9908\&compose $=\&$ first $=1 \&$ uid $=$ WEEvREdxOWJmbC9oM1NjYkZCbDdrdWdXNUoyeW5ZOWZ4OTU4 WEpaNzVPU1|=\$R1yZOH6jyaaOen3RxVUd8df-oHi7XMMDo7mtKT6 mSmEvTuk11 12gFA!! Chinese Journal:(张俊彦.多孔材料的力学性能及破坏 机理.湘潭大学.2003).

\section{Publisher's Note}

Springer Nature remains neutral with regard to jurisdictional claims in published maps and institutional affiliations.

Ready to submit your research? Choose BMC and benefit from:

- fast, convenient online submission

- thorough peer review by experienced researchers in your field

- rapid publication on acceptance

- support for research data, including large and complex data types

- gold Open Access which fosters wider collaboration and increased citations

- maximum visibility for your research: over $100 \mathrm{M}$ website views per year

At BMC, research is always in progress.

Learn more biomedcentral.com/submissions 